\title{
About some relationships between Knowledge and Context
}

\author{
J.-Ch. POMEROL and P. BRÉZILLON \\ LIP6, Case 169, University Paris 6, 4 place Jussieu, 75252 Paris Cedex 05, France \\ E-mail: \{Jean-Charles.Pomerol, Patrick.Brezillon\} @lip6.fr
}

\begin{abstract}
Many attempts have been made to capture, on the one hand, the nature of knowledge, and on the other hand, the nature of context. In this paper, we compare the two concepts of context and knowledge which, obviously, share some common aspects. Rather than trying to precisely define knowledge and context, we review the generally proposed characteristics of both concepts and while we conclude to a large overlapping of the two concepts, we also emphasize their differences as regards decision making and action.
\end{abstract}

\section{Introduction}

On the one hand, many attempts have been made to capture the very nature of knowledge. These analyses come from different fields: philosophy, cognitive science, artificial intelligence, etc. On the other hand, there is now a renewal of the studies on context and several proposals to represent and implement the context in "intelligent" systems.

Up to now, there were, as far as we know, few attempts to compare the two concepts of context and knowledge, while they obviously share some common aspects. In this paper, we review the main characteristics of both concepts as they appear in the engineering field and, while we note a large overlapping of the two concepts, we also emphasize their differences as regards decision making and action.

We start by reviewing, in Section 2, the most famous views and definitions of knowledge. In the next section, we give some characteristics of knowledge that seems important as regards to context. In the fourth section, we introduce the notion of context with its main components. Then, we stress, in Section 5, the differences between knowledge and context.

\section{What is Knowledge for Computer Scientists?}

Researchers in computer science, mainly in artificial intelligence (AI) generally try to define knowledge by a progressive process of construction going back to data, which are the symbols perceived by an subject whether these data are already structured either by the perception device or by the machine which conveys them. From data emerges information which is data with a strong semantic content. Thus, information is structured data with a semantic content expressible by natural language. Information 
is generally framed by a subject but it is sharable and is immediately usable by human beings on the basis of their knowledge. It is sometimes argued that context is used both to transform data into information (Wilson, 1984; Zack, 1999) or/and to acquire knowledge (Anderson, 1995; Brézillon and Pomerol, 1996). We will come back on these issues in the fith section.

The next transformation in the appropriation process is the passage from information to knowledge. This appropriation process relies on prior knowledge and is made consistent with the values and beliefs of a subject. For example, according to the previous more or less common views, Aamodt and Nygard (1995) distinguish between data, information and knowledge. Furthermore, these authors propose to consider data as input in the interpretation process, i.e. in the initial step of decision making. In this scheme, the data are the stimuli which enter the interpreter according to the classical view of the Information Processing Systems of Newell and Simon (1972). Information is then data with a meaning visible or understandable i.e. with a structure or which can be expressed by a language. This is the output from data interpretation as well as the input of the knowledge-based process of decision making. Knowledge is information incorporated in an agent's reasoning and made ready either for active use within a decision process or for action. It is the output of a learning process. Thus, the roles of knowledge are to: (1) transform data into information, (2) derive new information from existing ones, and (3) acquire new knowledge pieces. We have summarized Aamodt and Nygard's viewpoint on Figure 1. The interpretation process adds structure and expressiveness to data, transforming data into information. The second box corresponds to the transformation of information into knowledge. At this point, we cannot hide that knowledge must have also some validity. This is why knowledge is often defined as "justified true belief". This paves the way to new questions : what is justified and who justifies? In a word, does a person who know everything about astrology has some knowledge for an observer who does not believe into astral influence?
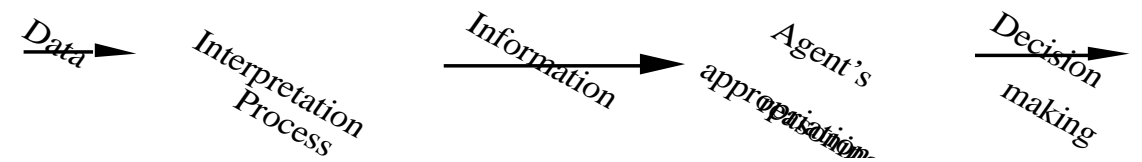

Figure 1 : From data to action (adapted from Aamodt and Nygard (1995))

The main differences between information and knowledge results from the appropriation process and the re-thinking of information in an organized meaningful corpus with consequential and causal links. In other words, knowledge is the information that is integrated and understood in the mind of a given subject. One of the difficulties with this definition is that knowledge is necessary to transform data into information and that knowledge is the result of the appropriation process (learning). It follows that knowledge is both a means and a result of this complex process; knowledge must be managed as an object and a process (Zack, 1999). Another difficult question is that some knowledge is also necessary to structure the unorganized stimuli emerging from the "primordial symbolic soup" and to shape rough stimuli into data. In artificial systems, the structuration introduced by the sensors results from the designer's intelligence. For animals as well as human beings, one can invoke a 
transcendental hand or evolution. This leads to the well known philosophical paradox stating that "knowing comes before recognizing" but, in this case, from where knowing comes ? At least this last problem does not occurs in automatic pattern recognition because the knowledge is provided by the designer of the system.

We can sum up our view in a scheme (Figure 2) which is far from being original since these ideas, at least the different layers, are more or less commonplace in the Artificial Intelligence community, although not always so clearly stated.

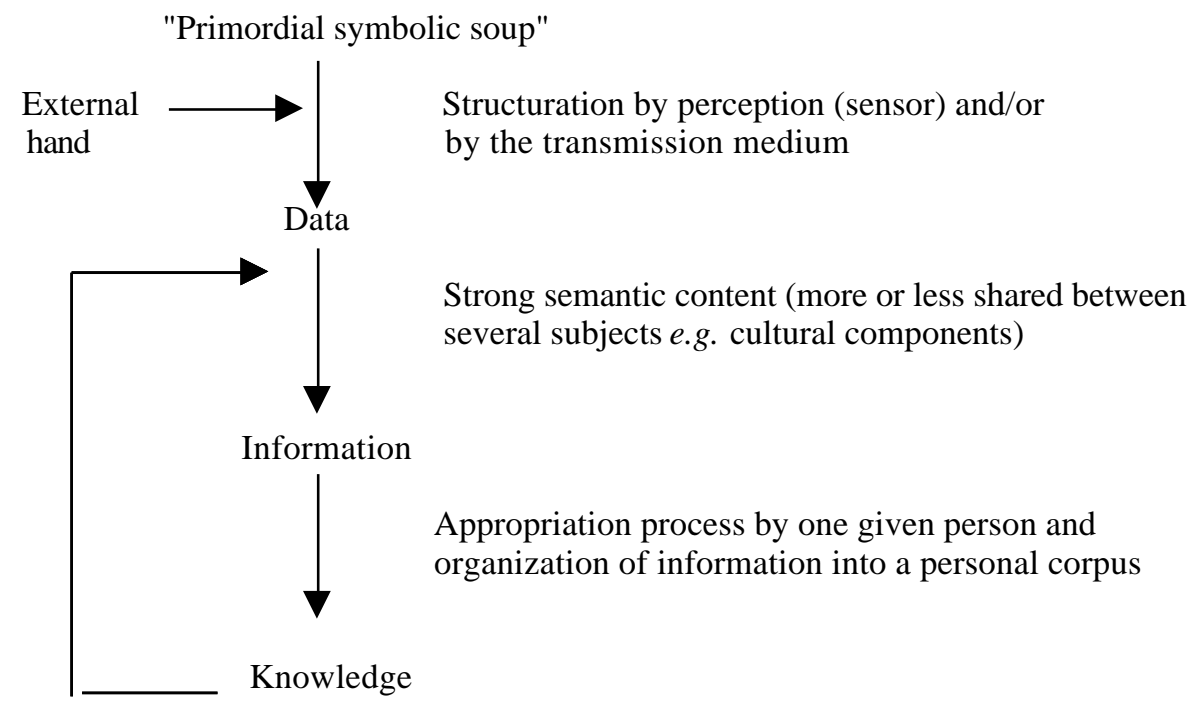

Figure 2: From the "primordial symbolic soup" to knowledge

An extra layer to the scheme of Figure 1 has been added by some authors (e.g. Ackoff, 1978; Godbout, 1998) this is the notion of wisdom. In the Al tradition, we think that this can be interpreted as meta-knowledge, namely the knowledge necessary to use knowledge (Pitrat, 1990). In other words the meta-knowledge is the knowledge mobilized to acquire new knowledge and update it; these two actions are usually referred as learning. Let us also mention that philosophical views refer to wisdom as the level devoted to the evaluation of knowledge especially as regards values and morality. 


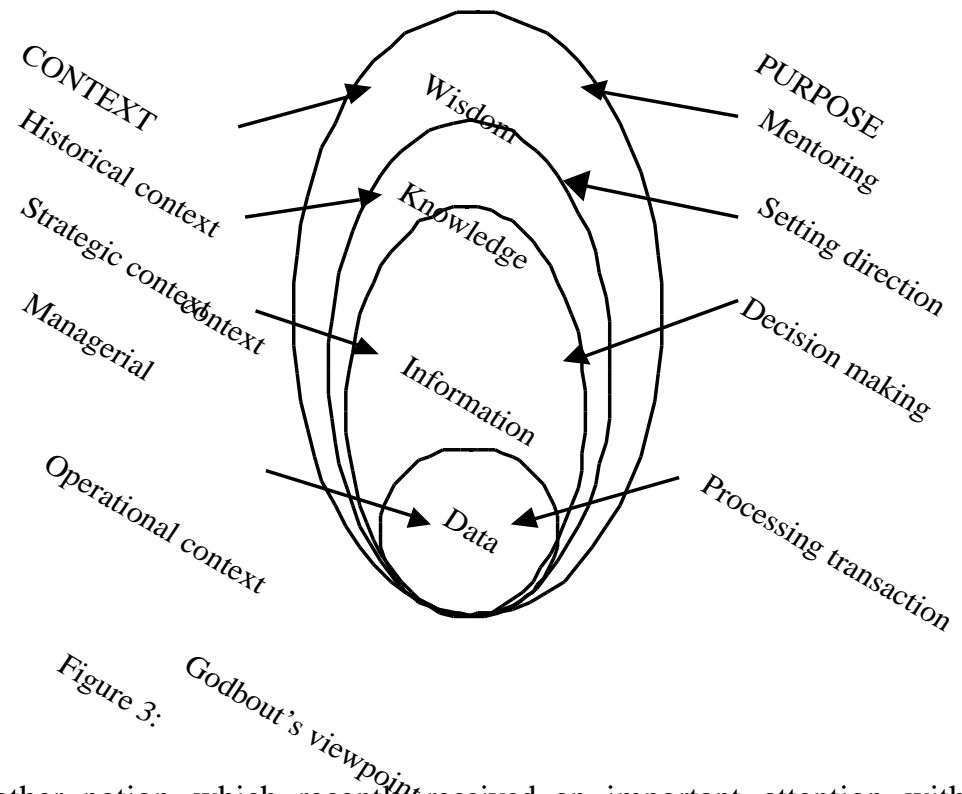

Another notion which recentlys seceived an important attention within the AI community is the notion of contexparsee Brézillon, 1999, for a survey). The articulation of context with knowledge is the subject of this paper. Godbout (Figure 3) tried to relate different level of context to the "knodedge ladder". We do not adhere to this scheme as long as in the different contexts pointed out by Godbout, we could change "context" by "knowledge" without altering the preaning of the scheme. It seems that in Godbout's scheme the word "context" is used in prace of "knowledge" to avoid the just mentioned difficulty : namely some kind of knowledge is necessary to climb up the ladder from data to wisdom!

However these basic ideas about knowledge being recalled, let us now examine what are the main attributes and modes of knowledge.

\section{Knowledge characteristics}

One of the first distinction between the different forms of knowledge in an operational setting goes back to Ryle (1949). This concerns know how versus know that. The term know how refers to the knowledge that people use to operate or behave as opposed to theoretical knowledge which is related to the profound, ultimate and often hidden causes of the on-going phenomenon. Carr (1981) defines know how as essentially different from theory while expressed by rules: "Inter alia, knowing how in the strong sense to play football is knowing the rules of the game, but a statement of the rules of the game is not a theoretical statement but a description of a set of rules of practice, and mastery of the rules brings with it an understanding of an activity rather than a theory. Statements of the rules of a game are essentially of relations between prescription...", Carr (1981) quoted by Wallis (2000). In Carr's example we can guess that theoretical knowledge about football would explain the genesis of the rules and the ultimate origin and the social role of this particular game. 
This distinction between "theory" and "practice" is commonplace in many domains close to cognitive science. However, we will see that practice is more context dependent than theory. In the AI field, the previous distinction is intertwined with the discussion about deep and surface knowledge (see e.g. Steels (1990)). It is commonly admitted in AI that deep knowledge refers to models and causal explanations that goes back to nature laws, whereas the surface knowledge is represented by practical rules that can be acquired from people performing efficiently a given task (human experts). Thus, we see that, on the one hand, the deep knowledge is very similar to know that. On the other hand, it is not so clear that surface knowledge is equivalent to know how. The discussion deep vs. surface is contemporary to the distinction between procedural and declarative knowledge which was introduced in artificial intelligence by McCarthy and Hayes (1969). Roughly speaking the procedural knowledge is a knowledge which is expressed in expert systems by rules or, in organizational life, by procedures. Declarative knowledge refers to more descriptive knowledge represented by objects or agents in new programming languages. This distinction between rules and descriptive patterns like frames or objects is related to some psychological issues and the difference between rule-based behavior and more intuitive recognition-primed reactions has been early emphasized in AI (see e.g. Winograd (1975) and Anderson (1976)).

The notion of "practicability" offers another possible way of analysis. This has been renewed by the study of "communities of practice" (see Brown and Duguid, $(1991,2000)$ and Wenger (1998). This notion of practical knowledge is particularly relevant in learning because it has been observed for centuries that some knowledge needs apprenticeship (i.e. practice) to be learnt whereas some other does not necessitate such practice.

In few words, a French proverb states that it is by marshalling that you will become a marshal whereas, for example, you can learn about blood circulation and the role of the heart without dissection, because you trust your professor or a textbook. This discussion is not far from the previous one in the sense that deep knowledge is probably something which can be acquired without practice, but surface knowledge certainly cannot be assimilated without practice (Clancey, 1995). This last problem is recurrent in knowledge engineering, moreover the lack of contextual information about the task at hand has been recognized as a weakness of rule-based systems (Brézillon and Pomerol, 1996). In apprenticeship the contextual information is acquired by doing. Actually, mastery in a job may partly results from some rules which are given by masters but practice or knowing how cannot be reduced to rules, this is just the first reason why apprenticeship is necessary. The second reason is that learning is a social process as underlined by the literature on community of practice (Brown and, Duguid, 1991, 2000; Wenger, 1998). However, learning deep knowledge is probably also a social process of another kind and it is not likely that isolated individuals can learn everything in books or on the web, see Brown and Duguid (2000) for a discussion on this last point.

The question of the practical knowledge nature opens another discussion about tacitness versus explicitness. A first discussion refers to explicit vs. implicit beliefs (Levesque, 1984). This discussion has been recently enlightened by Nonaka (1994) who distinguishes explicit and implicit knowledge and the movements between them (see also Cleeremans (1997), Dienes and Perner (1999), Crowley (2001)). Explicit knowledge is easily shared whereas implicit knowledge is highly personal. This last type of knowledge is not articulated and is mixed with emotions (Damasio, 1994); it 
is the result of some internal processing (Polyani, 1962). In decision making, this is reminiscent to Klein's Recognition-Primed Decision (1993). The discussion about tacit versus explicit knowledge is not far from knowing how versus knowing that while it stresses the appropriation components. The tacit knowledge implicitly belongs to somebody whereas explicit knowledge can be shared and is generally public. We would also distinguish between tacit knowledge which can be explicited and non-explicitable tacit knowledge, even if this latter can be shared in a community of practice. This is the case of many handling skills in a lot of craft jobs.

The consciousness of knowing that was a point already made by Ryle (1949) moreover consciousness implies that knowing that can be explained and shared with other thinking subjects, but neither necessarily reduced to rules nor explicited. The notions of procedural and declarative knowledge have been brought into contact with the implicit-explicit distinction by several authors. For instance Karmiloff-Smith (1986, 1992) characterized implicit knowledge as a procedural knowledge whose accessibility for the other parts of the system is limited. Accessibility has also been emphasized as the central issue in the distinction between procedural and declarative knowledge by Kirsh (1991). Squire (1992) characterized the knowledge about the past that is typically impaired in amnesia as declarative memory (where declarative is largely considered as a terminological variant of explicit memory or knowing that) and contrasted this to non declarative memory (i.e. implicit knowing how) that includes procedural memory (habits, skills and conditioned reactions) but also memory of facts revealed by priming.

Between tacit and explicit knowledge, Nonaka describes four types of exchange: socialization, externalization, combination and internalization, as represented on the Figure 4. Knowledge socialization refers to the creation of new tacit knowledge from shared tacit knowledge. Knowledge externalization refers to the conversion of tacit knowledge into explicit knowledge (1995). Knowledge combination refers to the creation of new knowledge through the exchange and combination of explicit knowledge held by individuals in the organization. Knowledge internalization takes place when explicit knowledge becomes tacit, in a way similar to learning.

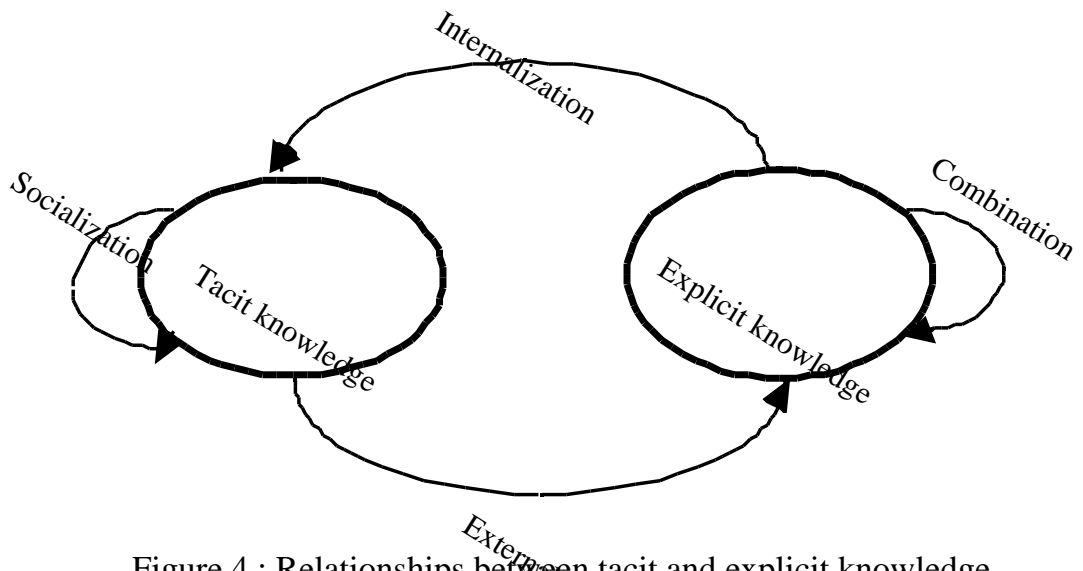

Figure 4 : Relationships bethen tacit and explicit knowledge (Nonaka and Takejuchi, 1995) 
We think that the main contribution of Nonaka is not the distinction between tacit and explicit knowledge but the study of the exchanges between these two types of knowledge. The process of externalization is especially interesting as regards context for it anticipates on the process of proceduralization that we have introduced in Pomerol and Brézillon (1999). This rises the question of why and when people decide to externalize. This question which is particularly important in process control (Brézillon et al., 1998; Pomerol and Brézillon, 1999). In this last framework, the development of automatic control systems supposes that knowing how has been previously captured. Knowing that may explain parts of knowing how but is never sufficient to control complex process whence the idea of cooperative or interactive systems in which operators work in interaction with a system. For example, mechanics laws can explain how and why bikes run but a bit of practice is necessary to ride a bike. This last example shows that the links between deep knowledge and practice are never necessary because many people ride a bike wihtout any idea about mechanics.

If we were obliged to distinguish between the two types of knowledge, we would conclude that the AI community made a good point about deep and surface knowledge. Our observations in engineering and process control lead us to emphasize the distinction between deep knowledge and know how. As regard know that we believe that this notion can be assimilated to deep knowledge but we prefer the latter because it captures the fact that this knowledge is generally not immediately sensible.

The distinction between tacit and explicit is also important whereas we believe that any kind of knowledge can be made explicit or implicit depending on the circumstances, the persons and the society. This is the reason why we prefer to stress the question of how to explicit hidden know how even if we guess that there is a part of knowing how which is definitely non explicitable. These are the central questions for developing "intelligent" assistant systems (Brézillon and Pomerol, 1999)

One of the last characteristics of know how which have already been recognized is that know how is task specific (Wallis, 2000) and is related, whereas not similar, to ability (Ryle, 1949; Carr, 1981; Wallis, 2000). The AI community introduced the term of situated action (Clancey, 1991, 1992). This rises the question of the acquisition of the context of the know how and of the validity of the know how. For example, somebody may have know how for sailing in a bay and may have great difficulties on open sea with a bad weather. In other words, knowing how gives some abilities which are dependent on the context of application. Thus, before we examine the relationship between context and knowledge, let us remind some basics about context.

\section{Context}

There is already a large amount of discussion about context (see Brézillon, 1999, for a survey in AI). From an engineering point of view we can start from a definition of context as the collection of relevant conditions and surrounding influences that make a situation unique and comprehensible (Hasher and Zacks, 1984; Anderson, 1995). The difficulty with this definition is that there are "numerous interacting factors that people do not even pay attention to on a conscious level, and many of which are outside the ability of machine input devices to capture" (Degler and Battle, 2001). 
Let us take an example, in the control of a subway line (Brézillon et al, 1998), here a large amount of knowledge about trains, electricity, people reaction, etc., contributes to make the situation unique, while some more particular conditions about the time, the day, the weather and so on, influence specifically many decisions. In other words, there is a common background context which is then specified by some conjecture and contingent influences. For example, the general context is subway control which differs from train or bicycle control although they share some mechanical laws and the particular context is specific to a line, a day, an hour, etc. These considerations explain why Tiberghien (1986) defines context as the whole set of secondary characteristics of a situation or secondary properties of a cognitive or motivational state of an individual which may modify the effect of an effective stimulation (stimulus) or an oriented activity.

Thus, it would probably wise to talk of primary and secondary context to distinguish between the general, relatively fixed primary characteristics of a situation, and the secondary characteristics which are more mobile. If we think about primary context, we must confess that it is difficult to avoid the word knowledge about this general background used by the operators to carry out their task. This is the reason why we have proposed (Brézillon and Pomerol, 1999) to call "contextual knowledge" the primary or back-stage context.

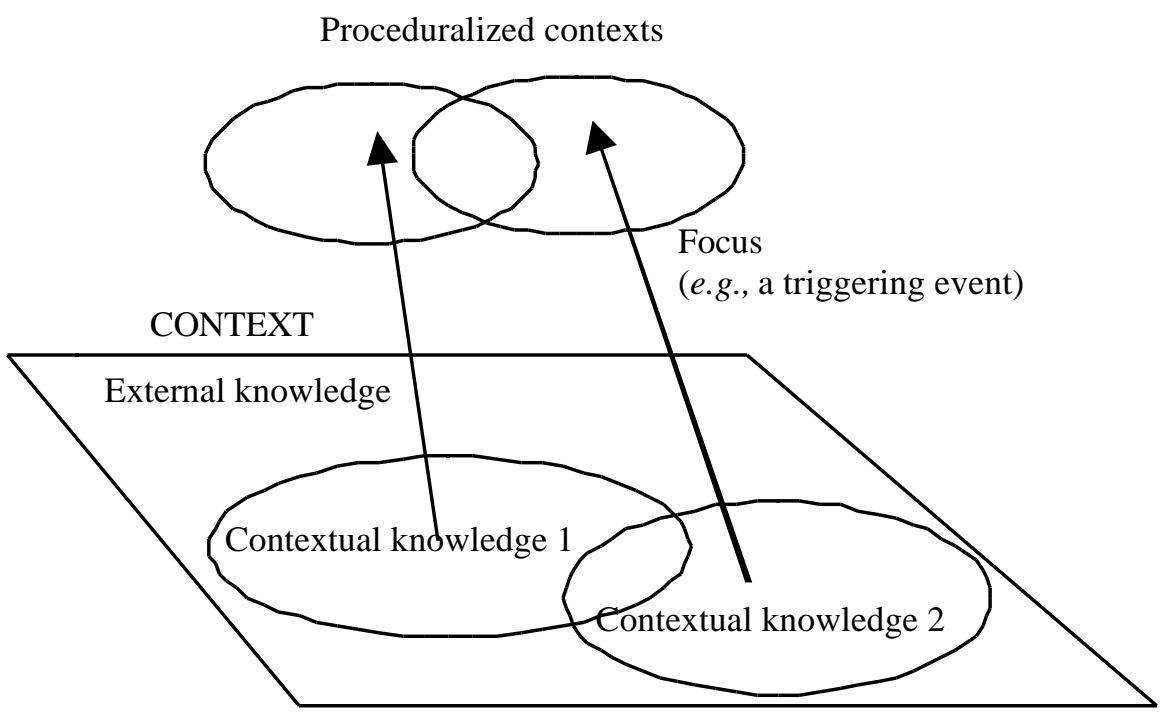

Figure 5: Contextual knowledge and proceduralized context

Therefore, at a given step of a decision process or of a task performing, we distinguish between the part of the context which is relevant at this step of the decision making or task performing, and the part which is not relevant. The latter part is called external knowledge. The former part is called contextual knowledge, and obviously depends on the agent and on the decision at hand. At a given step of the decision making, a part of the contextual knowledge is proceduralized. We call it the proceduralized context. The proceduralized context is a part of the contextual knowledge which is invoked, structured and situated according to a given focus. 
Ozturk and Aamodt (1998) proposed a quite similar distinction between external context (our contextual knowledge) and internal context (our proceduralized context). In our field studies (Brézillon et al., 1998) about the task of incident solving, we observed that a part of the contextual knowledge is known a posteriori, since some elements appear to be important to understand, explain or solve the incident only during the incident solving, not beforehand. For one given incident, the frontier between the subset of contextual knowledge and the subset of external knowledge is fixed, we just don't know, before the incident, if an element is a part of contextual or external knowledge. This observation is similar to Edmonds's view (1997) for which it is better not to distinguish context from other objects of reasoning, learning, etc., objects being in the context or not according to circumstances.

The contextual knowledge is a backstage knowledge whereas proceduralized context is immediately useful for the task at hand. In our representation of context, the contextual knowledge is largely tacit, mainly because it is the context that everybody knows without expressing it. In a distinction reminiscent to cognitive ergonomics (Leplat and Hoc, 1983), we could say that the contextual knowledge is useful to identify the activity whereas the proceduralized context is relevant to characterize the task. It is also worth noting that Leplat and Hoc observe that the tasks correspond to the explicit aspect of the work while activities are rather implicit. The distinction between practical and theoretical knowledge or knowing how versus knowing that is not relevant here. The contextual knowledge can encompass both types of knowledge.

An important issue is the passage from contextual knowledge to proceduralized context. This proceduralization results from the focus on a task. Thus, it is taskoriented just as knowing how; it is often triggered by an event or primed by the recognition of a pattern. Another aspect of proceduralization is that the operators transform contextual knowledge into some functional knowledge or causal and consequential reasoning in order to anticipate the result of their own action (see also Decortis et al., 2000, for a similar observation). Thus, the functionalization is a part of the proceduralization process, and this is the reason why we have chosen the term of proceduralization. This functionalization, or proceduralization, obeys to the necessity of having a consistent explicative framework to anticipate the results of a decision or an action. This consistency is obtained by reasoning about causes and consequences in a given situation. We can thus separate the reasoning between diagnosing the real context and anticipating the follow up (Pomerol, 1997). The second step needs a conscious reasoning about causes and consequences. This explicit reasoning in the mind of the subject has also been recognized by Levesque (1984) about beliefs, this is very close to our view.

A second proceduralization aspect is a kind of instantiation (see also Grimshaw et al., 2000) This means that the contextual knowledge or background context needs some further specifications to perfectly fits to the task at hand. These precisions and speciation brought to the contextual knowledge is also a part of the proceduralization process.

We also observed that the construction of the proceduralized context from contextual knowledge is often a process of communication in the operator community. Figure 6 represents how the proceduralized context is built from contextual knowledge during the interaction between two agents. The interaction context contains proceduralized pieces of knowledge in the focus of attention of the two agents. These pieces of knowledge are extracted from the contextual knowledge of 
each agent; they are jointly structured by the two agents and result in a shared knowledge. Generally, the first utterance of an agent gives a rule such as "Stop at the next station if the alarm signal is triggered". Then, on the request of the second agent, the first agent may add some pieces of knowledge related to his first utterance. If this knowledge chunk belongs to the common part of the contextual knowledge of the agents, the pieces are integrated into a mutually acceptable knowledge structure, and then is moved to the shared proceduralized context. Thus, the proceduralized context contains all the pieces of knowledge that have been discussed and accepted (at least made compatible) by all the agents. These pieces of proceduralized context will then become again a part of the shared contextual knowledge of each agent while it gets off from the focus of the proceduralized context. Later, this chunk of knowledge previously proceduralized may be recalled, as any piece of contextual knowledge, to be integrated in a new proceduralized context. Thus, the more an operator is experimented, the more the operator possesses available structured knowledge. This is very similar to the externalization process in Nonaka's sense. Let us also note that when proceduralized the context can be shaped in procedures whether implicit or explicit. This process of is very similar to the process of learning by chunking of SOAR (Newell, 1990). In other words, parts of contextual knowledge are compiled into short-cuts or implicit procedures as a result of learning.

The previous example of joint proceduralization explain that whereas the proceduralization process is primarily subjective, it can also be shared and results into some common context in communities sharing the same background and expertise.

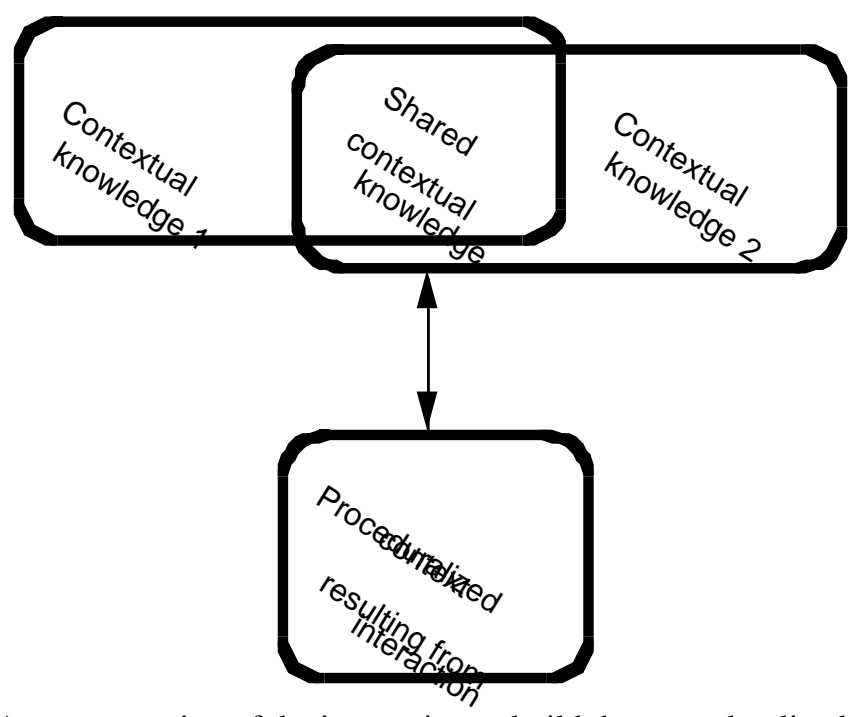

Figure 6 : A representation of the interaction to build the proceduralized context

The dynamics of contexts in any activity is a very important point (Lave, 1988; Nardi, 1996; Greenberg, 2001). We really observed that the main purpose of the operators is to diagnose the very context in which their decision or action takes place. This observation leads to the representation by contextual graphs (Brézillon et al., 2001). 
Finally, a last point deserves attention, it is the role of context in knowledge acquisition. Wilson (1984) defines information as data plus context. Accordingly it would be the context which supports data structuration and makes them readable to human beings. We cannot share this view because we cannot see how context can intervene per se, we think that people transform data into information and this transformation depends on the context but relies on knowledge. We are closer to Zack (1999) who states that data represent observations or facts out of context and that context is one of the elements of the transformation into information. Another view is that "knowledge is generated when information is combined with context and experience" (Huang et al., 1999) quoted in Degler and Battle (2001). We certainly agree that, on the one hand, experience is a part of knowledge construction. On the other hand, we are convinced for a long time Karsenty and Brézillon (1995) and Brézillon and Pomerol (1996) that the context intervenes in learning but, once more, we think that even if the context is necessary to "situate" knowledge and if what is learnt must be re-used in the context of acquisition, we do believe that an important part of knowledge is either non-contextual or de-contextualized in the mind. This is one of the reasons why we think that knowledge is not as appropriate as context for system design as we will explain in the next section.

\section{Context is related to decision and action}

The first distinction between context and knowledge or information which is generally acknowledged is that context is task-oriented or is, at least, related to an activity (Nardi, 1997). All the authors we reviewed using the notion of context relate the notion to some specific framework of decision and/or action. For example, the fact that we know that the nearest star after the sun is Proxima Centauri at 4.22 light-years will never be contextual knowledge except for an astronomer or people engaged in star trek! Whether it is backstage contextual knowledge or immediately usable knowledge, depends on what a subject intends to do. So, the context is primarily subjective, even if it can be shared in a community according to the process previously described.

These two characteristics (1) task oriented and (2) subjective are also two components of know how. This does not mean that the two concepts are similar, since the contextual knowledge can contain some theoretical knowledge. For example, in many tasks, a contextual element which is taken into account is the gravity. By the way, this element is typically not a secondary specification and is therefore a part of contextual knowledge, moreover the intensity and the role of gravity is obviously a matter of theory. We therefore think that the context is not reduced to surface and declarative knowledge and can also involve deep knowledge.

Context is task oriented or more precisely the proceduralization process is taskoriented even task-focused and/or recognition-primed. During this passage from back to front stage some information are instantiated, this is like new information that is provided about the events in a uncertain setting. At a given moment, we do not know the true nature state, then after a while, some events are known which give more information on the true nature state. According to this comparison, in our model, a context has many possible realizations just as an event in decision theory. This means that the contextual knowledge has many variables and that the proceduralization process is partly an instantiation process. One can say that knowing how is instantiated in doing. The proceduralized context is an instantiation of a part of the 
contextual knowledge. This instantiation gives the keys for decision making or action. Proceduralized context is sufficient for action but only people with the adequate knowing how can bridge the gap between proceduralized context and action. The proceduralized context triggers some entailment links for people knowing how. As such it can be regarded either as a part of know how or as a signal triggering adapted answers to a situation.

The relationships between the proceduralized context and decision making or action are not necessarily explicit. A kind of compilation can occur that establishes some routine links between a proceduralized context and the subsequent action or anticipation. This is the functional side of the proceduralization.

To sum up, the differences and analogies between context and knowledge, are:

- context and knowledge can be explicit or implicit, but both can be explicited except for some parts of know how

- context can contain deep and/or surface knowledge,

- the contextual knowledge is loosely task-oriented not reduced to know how, because it may contain deep knowledge,

- the contextual knowledge is mainly concerned with this part of knowledge which is useful for describing the nature state preceding decision making or action; as such a given contextual knowledge may have several realizations,

- the proceduralization of a contextual knowledge piece is a subjective process which is a mandatory step on the road to action. As such, it has a role in diagnosing the situation, priming action or practice. In some sense, it is the preliminary step for the activation of knowing how. In some case the proceduralization can be a shared process within a community,

- the proceduralized context is task-oriented or/and recognition-primed and subjective like know how or situated knowledge,

- the link between proceduralized context and action is either explicit or implicit (compilation of the proceduralized context). As such, the proceduralized context is relevant to the so-called externalization process (Nonaka, 1994). This externalization process is a more or less a social process,

- $\quad$ whereas the knowledge is fixed, the proceduralized context changes during action.

In an overly simplification of our position we can summarize on Figure 7 the relationships between context and knowledge. Know how is a practical knowledge which is task-oriented. Know that or deep knowledge is not related to a particular task. The contextual knowledge is a subset of the whole knowledge which can contains deep and surface knowledge and is loosely related to the task but is related to general activity while the proceduralized context is exactly what is necessary to perform the task.

Proceduralized context

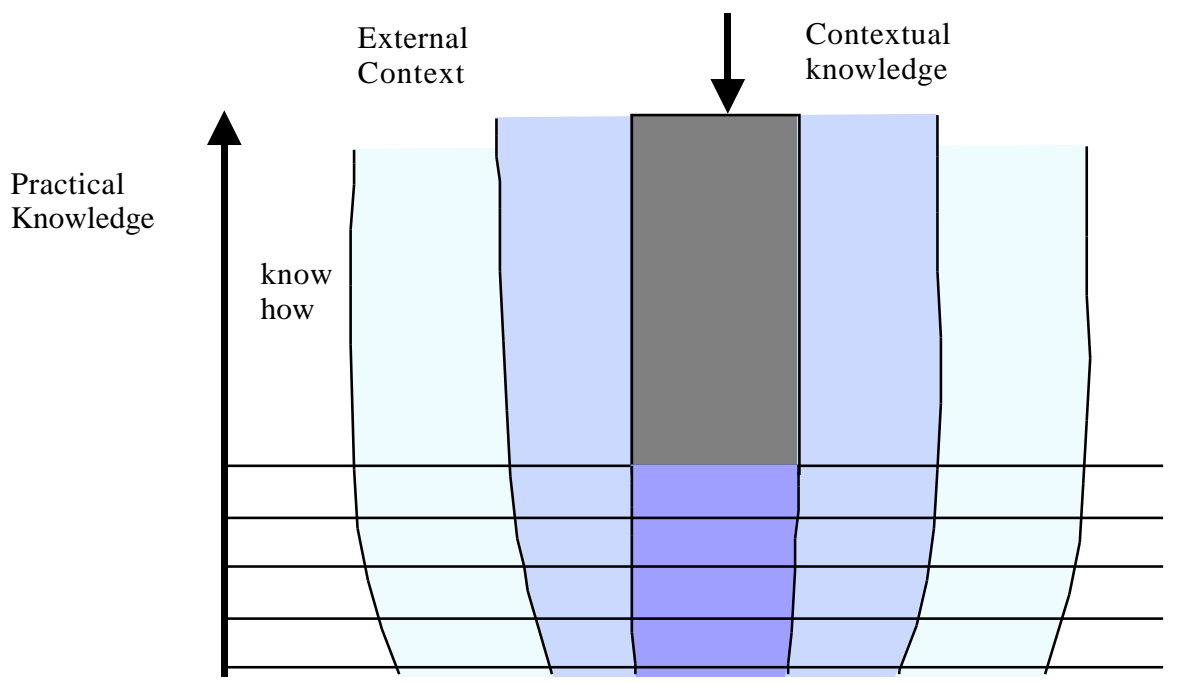


Deep

Knowledge

Figure 7 : The different types of context

In Figure 7 we do not try to capture all the dimensions of knowledge. We do not discuss the nature of other knowledge whether it is theoretical or practical. This is very discussible because following Hatchuel and Weil (1992) we should consider know how, understanding (i.e. know that) and relating-combining skills (i.e. the strategic knowledge creating links and relationships). Figure 7 is therefore misleading because it assumes that practical knowledge and know that realize an exact partition of the knowledge. Moreover it does not do justice to the many other dimensions of knowledge and the various levels of reasoning. In particular we are unable to posit the know how on this figure because it is not entirely contained in the knowledge plan due to the automatisms that are a part of any good handling. The projection of know how on the figure plan would be the upper part of the proceduralized context.

Thus, it is clear that context and knowledge have many similarities and links, but they nevertheless differ. Context is different from knowing how, but is similarly subjective and task-oriented. Context is mainly descriptive knowledge more or less used to describe nature states but can contains a part of deep knowledge. Contextual knowledge obeys to a dynamics of instantiation and functionalization during action. Finally, we do believe that knowledge is a too vague concept to be really operant in the analysis of decision making and of task undertaking. On the contrary, the notion of context which is entirely task oriented offers a shrewder concept to model the relationships between knowledge and action. 


\section{Conclusion}

The notion of context offers an alternative view to knowing how to capture that part of knowledge which is related to decision making and action. Contextual knowledge is subjective and yet can be shared by many individuals. One of the main difference between context and knowledge is that context and its proceduralization offer a model to understand the links between decision making and/or action and the backstage knowledge used in a given activity. The notion of context does certainly not explain know how, but it help to understand how experienced people with a recognized know how adapt their behavior according to the circumstances. In some sense, context is knowledge about the instantiation of know how, it is the framework which reveals know how.

\section{References}

Aamodt A. and Nygard M. (1995) Different roles and mutual dependencies of data, information, and knowledge - An AI perspective on their integration, Data and Knowledge Engineering (North-Holland Elsevier), 16, 191-222.

Ackoff R.L. (1978) The art of problem solving, John Wiley and Sons, NY.

Anderson J.R. (1976) Language, Memory and Thought. Hillsdale, Erlbaum NJ.

Anderson J.R. (1995) Cognitive psychology and its Implications, Freeman, New-York.

Brézillon P. (1999) Context in problem solving: A survey, The Knowledge Engineering Review, 14(1), 1-34.

Brézillon P. and Pomerol J.-Ch. (1996) Misuse and nonuse of knowledge-based systems: The past experiences revisited. In Implementing Systems for Supporting Management Decisions, Humphreys P., L. Bannon, A. McCosh, P. Migliarese and J.Ch. Pomerol (Eds), Chapman and Hall, London, 44-60.

Brézillon P. and Pomerol J.-Ch. (1999) Contextual knowledge sharing and cooperation in intelligent assistant systems, Le Travail Humain 62 (3), PUF, Paris, 223-246.

Brézillon P., Pomerol J.-Ch. and Saker I. (1998) Contextual and contextualized knowledge: An application in subway control, Special issue on Using Context in Application, International Journal on Human-Computer Studies 48 (3), 357-373.

Brézillon P., Pasquier L. and Pomerol J. Ch. (2001) Reasoning with contextual graphs. European Journal of Operational Research (to appear).

Brown J.S. and Duguid P. (1991) Organizational learning and communities of practice: towards a unified view of working, learning and organization, Organization Science 2 (1), 40-57.

Brown J.S. and Duguid P. (2000) The social life of information, Harvard Business School Press.

Carr D. (1981) Knowledge in Practice, American Philosophical Quarterly 18, 53-61.

Clancey W.J. (1991) Israel Rosenfield, The Invention of Memory: A New View of the Brain (Book Review), Artificial Intelligence 50, 241-284.

Clancey W.J. (1992) Model construction operators, Artificial Intelligence 53, 1-115.

Clancey W.J. (1995) Practice cannot be reduced to theory: Knowledge, representations and change in the workplace, in Organizational Learning and Technological Change, S. Bagnara, C. Zuccermaglio and S. Stacky (Eds), Springer, Berlin, 16-46.

Cleeremans A. (1997) Principles for implicit learning. In D. Berry (Ed.), How implicit is implicit learning ?, Oxford University Press, 195-234.

Crowley B. (2001) Building Useful theory : Tacit Knowledge, Practitioner Reports and Culture of LIS Inquiry, Journal of Education for Library and Information Science, in Press. http://domin.dom.edu/faculty/crowbill/ building.htm. 
Damasio A.R. (1994) Descartes' Error, Putnam's Sons, New York.

Decortis F., Noirfalise S. and Saudelli B. (2000) Activity theory, cognitive ergonomics and distributed cognition: three views of a transport compagny, Int. J. Human-Computer Studies 53, 5-33.

Degler D. and Battle L. (2001) Knowledge Management in Pursuit of Performance : the Challenge of Context, http://www.pcd-innovations.com/kminpursuit/id3-m.htm

Dienes Z. and Perner J. (1999) A theory of Implicit Explicit Knowledge, Behavioral and Brain Sciences 22 (5).

Edmonds, B. (1997) A simple-minded network model with context-like objects. Proc. of the 2nd European Conference on Cognitive Science, Manchester, UK, April, 181-184.

Godbout A.J. (1998) Filtering knowledge: changing information into knowledge assets. Technical Document 9867. http://www.scoap.com/ki/articles/godbout/ godbout03.htm Greenberg S. (2001) Context as a Dynamic Construct, Context-01, to appear.

Grimshaw D.J., Mott P.L. and Roberts S.A. (2000) The role of context in decision making : some implications for database design, EJIS Conference to appear.

Hatchuel A. and Weil B. (1992) L'expert et le Système, Economica, Paris

Hasher L. and Zacks R.T. (1984) Automatic processing of fundamental information : the case of frequency of occurrence, American Psychologist 39, 1372-1388.

Huang K.T., Yang W.L. and Wang R.Y. (1999) Quality Information and knowledge, Prentice Hall, NJ.

Karmiloff-Smith A. (1986) From meta-processes to conscious access: Evidence from children's metalinguinstic and repair data, Cognition 23, 95-147.

Karmiloff-Smith A. (1992) Beyond modularity: A developmental perspective on cognitive science, MIT Press, Cambridge, MA.

Karsenty L., Brézillon P. (1995) Cooperative problem solving and explanation. Expert Systems with Applications, 8 (4), 445-462.

Kirsh D. (1991) When is information explicitly represented? In P. Hanson (Ed.) Information, Thought and Content, UBC Press.

Klein G.A., (1993) A recognition-Primed-Decision (RDP) model of rapid decision making, in G.A. Klein, J. Orasanu R Calderwood and C.E. Zsambok (Eds), Decision making in Action Models and Methods, Ablex, 138-147.

Lave J. (1988) Cognition in practice, Cambridge University Press, UK.

Leplat J. and Hoc J.M. (1983) Tâche et activité dans l'analyse psychologique des situations, Cahiers de Psychologie Cognitive 3, 49-63.

Levesque H.J. (1984) A logic of implicit and explicit belief. In Proceedings of the Fourth National Conference on Artificial Intelligence (AAAI-84), 198-202.

McCarthy J. and Hayes P.J. (1969) Some philosophical problems from the standpoint of artificial intelligence, in B. Mehler and D. Michie (Eds.), Machine intelligence, Vol 4, Edinburgh University Press.

Nardi B. (1996) Studying context : a comparison of activity theory, situated action models and distributed cognition, in context and consciousness : activity theory and humanComputer Interaction, B. Nardi (Ed.), MIT Press, Cambridge, 69-102.

Newell A. (1990) Unified Theories of Cognition, Harvard University Press, Cambidge MA. Newell A. and Simon H. (1972) Human Problem Solving, Prentice-Hall, Englewood Cliffs. Nonaka I. (1994) A dynamic theory of organizational knowledge creation. Organization Science, 5(1), 14-37.

Nonaka I. and Takeuchi H. (1995) The Knowledge-Creating Company. Oxford University Press, New York, NY.

Ozturk P. and Aamodt A. (1998) A context model for knowledge-intensive case-based reasoning, Special Issue on Using Context in Applications. International Journal on Human-Computer Studies, 48 (3), 331-355.

Pitrat J. (1990) Métaconnaissances, Hermès, Paris.

Polanyi M. (1962) Personal Knowledge: Toward a Post-Critical Philosophy, Harper Torchbooks, New York, NY. 
Pomerol J.Ch. (1997) Artificial Intelligence and Human Decision Making, European Journal of Operational Research 99, 3-25.

Pomerol J.Ch. and Brézillon P. (1999) Dynamics between contextual knowledge and proceduralized context. Modeling and Using Context (CONTEXT-99). In Lecture Notes in Artificial Intelligence, $\mathrm{n}^{\circ} 1688$, Springer Verlag, 284-295.

Ryle, G. (1949) The Concept of Mind, Barnes and Noble, New York.

Squire L.R. (1992) Memory and the hippocampus : A synthesis from findings with rats, monkeys and humans, Psychological Review 99 (2), 195-231.

Steels L. (1990) Components of Expertise, AI Magazine, Summer, 28-49.

Tiberghien, G. (1986) Context and cognition: Introduction, Cahier de Psychologie Cognitive, 6 (2), 105-119.

Zack M.H. (1999) Managing codified knowledge, Sloan Management Review 40 (4), 45 58.

Wallis C. (2000) Consciousness, context and know how. http://www. arts.uwaterloo.ca/ cwallis/carr.htm

Wenger E. (1998) Communities of practice, Cambridge University Press, New York.

Wilson B. (1984) Systems : Concepts, Methodologies and Applications, John Wiley and Sons, Chichester.

Winograd T. (1975). Frame representations and the declarative-procedural controversy, in D.G. Bobrow \& A. Collins (Eds.), Representation and Understanding, 185-210. 